EPJ Web of Conferences 59, 02007 (2013)

DOI: $10.1051 /$ epjconf/20135902007

(C) Owned by the authors, published by EDP Sciences, 2013

\title{
Symmetry tuning with megajoule laser pulses at the National Ignition Facility
}

\author{
J.L. Kline ${ }^{1}$, N.B. Meezan ${ }^{2}$, D.A. Callahan², S.H. Glenzer ${ }^{2}$, G.A. Kyrala ${ }^{1}$, \\ S.N. Dixit ${ }^{2}$, R.P.J. Town ${ }^{2}$, R. Benedetti ${ }^{2}$, D.K. Bradley² ${ }^{2}$ E. Bond ${ }^{2}$, P. Di Nicola², \\ E.L. Dewald ${ }^{2}$, T. Doeppner ${ }^{2}$, S. Glenn ${ }^{2}$, C. Haynam², R.F. Heeter ${ }^{2}$, \\ D.E. Hinkel ${ }^{2}$, N. Izumi ${ }^{2}$, K. Jancaitis ${ }^{2}$, O.S. Jones ${ }^{2}$, D. Kalantar ${ }^{2}$, J. Kilkenny ${ }^{3}$, \\ K.N. LaFortune ${ }^{2}$, O. Landen², T. Ma², A. MacKinnon², P. Michel ${ }^{2}$, J.D. Moody ${ }^{2}$, \\ M. Moran ${ }^{2}$, T. Parham ${ }^{2}$, R.R. Prasad, ${ }^{2}$ H.B. Radousky, ${ }^{2}$ J. Ralph, ${ }^{2}$ \\ M.B. Schneider, ${ }^{2}$ N. Simanovskaia ${ }^{2}$, C.A. Thomas ${ }^{2}$, S. Weber ${ }^{2}$, K. Widmann, \\ C. Widmayer ${ }^{2}$, E.A. Williams ${ }^{2}$, B. Van Wontergheman ${ }^{2}$, M.J. Edwards ${ }^{2}$, \\ L.J. Suter ${ }^{2}$, L.J. Atherton ${ }^{2}$ and B.J. MacGowan ${ }^{2}$
}

${ }^{1}$ Los Alamos National Laboratory, Los Alamos, NM 87545, USA

${ }^{2}$ Lawrence Livermore National Laboratory, Livermore, CA 94551, USA

${ }^{3}$ General Atomics, San Diego, CA 92121, USA

\begin{abstract}
Experiments conducted at the National Ignition Facility using shaped laser pulses with more than $1 \mathrm{MJ}$ of energy have demonstrated the ability to control the implosion symmetry under ignition conditions. To achieve thermonuclear ignition, the low mode asymmetries must be small to minimize the size of the hotspot. The symmetry tuning experiments use symmetry capsules, "symcaps", which replace the DT fuel with an equivalent mass of $\mathrm{CH}$ to emulate the hydrodynamic behavior of an ignition capsule. The x-ray selfemission signature from gas inside the capsule during the peak compression correlates with the surrounding hotspot shape. By tuning the shape of the self-emission, the capsule implosion symmetry can be made to be "round." In the experimental results presented here, we utilized crossbeam energy transfer [S. H. Glenzer, et al., Science 327, 1228 (2010)] to change the ratio of the inner to outer cone power inside the hohlraum targets on the NIF. Variations in the ratio of the inner cone to outer cone power affect the radiation pattern incident on the capsule modifying the implosion symmetry.
\end{abstract}

\section{Introduction}

To successfully achieve indirect drive inertial confinement fusion (ICF), the implosions must maintain spherical symmetry to produce the highest convergence minimizing the size of the central hot spot [1]. Through sensitivity studies of the ignition design [2, 3], the tolerances for low mode asymmetries have been determined $[4,5]$. For the indirect drive approach to ICF, a capsule is placed in the center of a cylindrical hohlraum made of a high $\mathrm{Z}$ material, typically gold. The laser beams are pointed to the walls of the hohlraum where they are converted to x-ray radiation used to ablate the capsule material driving the implosion. For the National Ignition Facility (NIF) [6], the lasers are configured in four cones of beams, two inner cones at 23.5 and 30 degrees with respect to the hohlraum axis and two outer cones at 44.5 and 50 degrees. The hohlraum has a laser entrance hole on both the top and the bottom and a set of the four beam cones entering through each. The lasers impinging on the hohlraum walls create rings of high $\mathrm{x}$-ray emission on top of the thermal background emission from the hohlraum walls, all

This is an Open Access article distributed under the terms of the Creative Commons Attribution License 2.0, which permits unrestricted use, distribution, and reproduction in any medium, provided the original work is properly cited. 

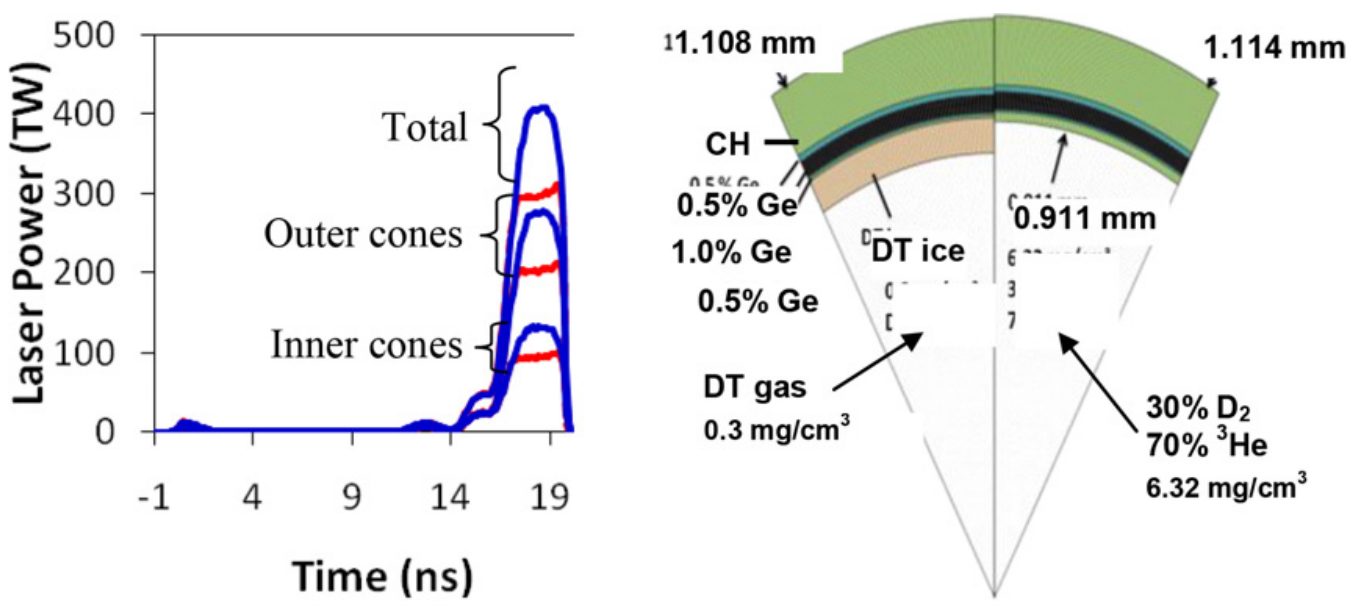

Figure 1. a) the laser pulse shapes for the (- - 1.0 and (-) 1.3 MJ laser pulse. b) Pie diagram of the ignition design and the companion symcap.

of which bathe the capsule in X-rays. The implosion symmetry can be controlled by varying the ratio of the incident power on the walls between the inner and outer beam cones, i.e. the cone fraction defined as the inner cone power divided by the total incident power. This changes the radiation pattern driving the capsule implosion. Previous experiments at the National Ignition Facility have demonstrated control of the incident cone fraction via crossbeam energy transfer [7, 8] that is determined by the difference in laser wavelength between the inner and outer beam cones [9-12]. This method employs scattering of the laser light from the outer beam cones to the inner beam cones via plasma waves driven ponderomotively by the beating of laser light. The methodology for computing the resulting incident cone fraction from hydrodynamic simulations is described by Town et al. [12] and was developed by Michel et al. [10].

To diagnose the implosion symmetry, symmetry capsules known as symcaps are used [13]. In a symcap, an equivalent mass of the capsule material, $\mathrm{CH}$ in the present case, replaces the DT fuel layer of an ignition capsule to mimic the same implosion profile as the ignition capsule, essentially conserving momentum. The cavity of the symcap is filled with a gas which emits xrays when heated by the capsule implosion at peak compression. A gated x-ray framing camera, using pinhole imaging, records the time history of the x-ray self-emission. The shape of this self-emission correlates to the shape of the remaining compressed shell surrounding fuel. To quantify the shape, contours of constant emission are decomposed using the Legendre polynomials and compared with simulations.

In this manuscript, we report on the first set of tuning experiments with shaped laser pulses having greater than $1 \mathrm{MJ}$ of laser energy. The experiments use the current hohlraum design for ignition and meet drive conditions consistent with the current ignition point design [3].

\section{EXPERIMENTAL SETUP}

The experiments use ignition scale hohlraums [3] heated with 192 laser beams of $351 \mathrm{~nm}$ laser light in the arrangement previously described. The shaped laser pulses have total energies of $\sim 1 \mathrm{MJ}$ and $1.3 \mathrm{MJ}$ with pulse lengths of $\sim 19.5 \mathrm{~ns}$ as shown in fig $1 \mathrm{~A}$. It should be noted that the $1.0 \mathrm{MJ}$ pulse is a clipped version of the $1.3 \mathrm{MJ}$ laser pulse. The total laser energy and power delivered by each quad is measured with $\pm 2 \%$ and $\pm 3 \%$ accuracy, respectively. The beams were smoothed using polarization smoothing, $45 \mathrm{GHz}$ Smoothing by Spectral Dispersion (SSD), and Continuum Phase Plates (CPPs) [14, 15]. The incident cone fraction is set to be $\sim .33$ during the main laser pulse while the actual incident laser 

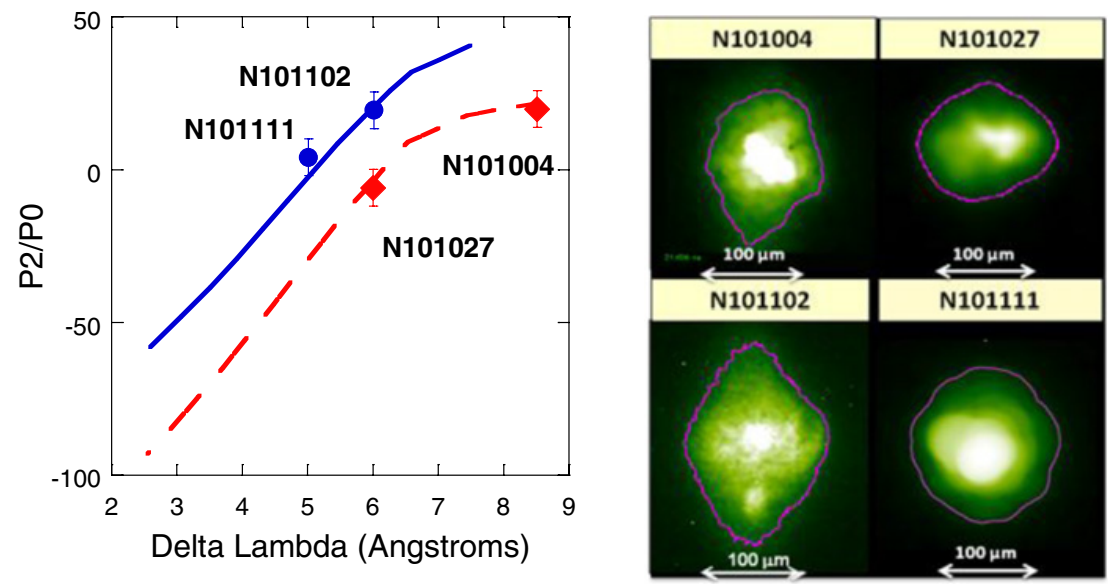

Figure 2. a) Calculated tuning curves for (- - 1.0 and (-)1.3 MJ with the experimental data at $(\bullet) 1.0 \mathrm{MJ}$ and $(\bullet)$ 1.3 MJ. b) Equatorial views of the self-emission for the symcaps with values: (N101102) P2/P0 $=20 \%$, (N101111) $\mathrm{P} 2 / \mathrm{P} 0=5 \%$, (N101004) $\mathrm{P} 2 / \mathrm{P} 0=19 \%$, and (N101027) $\mathrm{P} 2 / \mathrm{P} 0=-6 \%$.

pulse is calculated via hydrodynamic simulation. To change the incident cone fraction, the wavelength difference between the inner and outer beam cones is varied.

The hohlraums are $10.1 \mathrm{~mm}$ long with a diameter of $5.44 \mathrm{~mm}$ and has laser entrance holes that are $3.1 \mathrm{~mm}$ in diameter [3]. The symmetry capsules are $1.114 \mathrm{~mm}$ in diameter with a thickness of $203 \mu \mathrm{m}$ as shown in fig $1 \mathrm{~b}$. The capsules have layers of Ge doped $\mathrm{CH}$ to reduce preheat from Au m-band x-rays. $10 \mu \mathrm{m}$ of $\mathrm{CH}$ is used to simulate the DT fuel. The capsules for these experiments are filled with $30 \%$ Deuterium and $70 \%{ }^{3} \mathrm{He}$ designed to take advantage of the neutron and proton yields as diagnostics. The hohlraum targets are fielded at cryogenic temperatures between $24-32 \mathrm{~K}$ with a capsule fill density of $6.32 \mathrm{mg} / \mathrm{cm}^{3}$ and a hohlraum fill with He gas at a density of $0.96 \mathrm{mg} / \mathrm{cm}^{3}$.

Images of the capsule self-emission are collected with a CCD based gated x-ray detector [16] on the equator at 90-78 (Theta-Phi) in the NIF chamber coordinates [17]. A pinhole imaging snout is mounted to the GXD having a pinhole array with $8 \mu \mathrm{m}$ diameter pinholes. The pinholes are $\sim 80 \mathrm{~mm}$ from target chamber center where the implosion occurs. The detector is $1.2 \mathrm{~m}$ from TCC giving a magnification of $\sim 15 \mathrm{x}$. The pinholes are surrounded by 0.125 um of Kapton on both sides and a filter basket sits between the pinholes and GXD with $2 \mathrm{~mm}$ of Kapton to protect the $\mathrm{x}$-ray framing camera.

\section{RESULTS}

Results from both the 1.0 and 1.3 MJ symmetry tuning experiments are shown in figure 2a. The plot shows the tuning curves generated using the procedure described by Town et al. [12] for both 1.0 and 1.3 MJ. The offset between the two tuning curves is a result of the different plasma conditions generated with the different laser energies. Examination of the tuning curves shows that the dependence of the symmetry rolls over at large delta lambdas. This is a result of saturation in the amplitude of the ion acoustic wave that transfers energy between the inner and outer beam cones. For the crossbeam transfer model, the saturation level is set manually based on experimental data. Data from four laser experiments is plotted in Figure 2a with the tuning curves with the corresponding images in Figure 2b. The selfemission images for the four shots at peak emission have the contour used in the analysis for the images. For this analysis, the contour at $17 \%$ of the peak intensity is used, but other contours give the same result to within the error. The second Legendre coefficient, and higher, is determined from the shape of this contour. It should be noted that for these experiments it was discovered that ice was building up on 

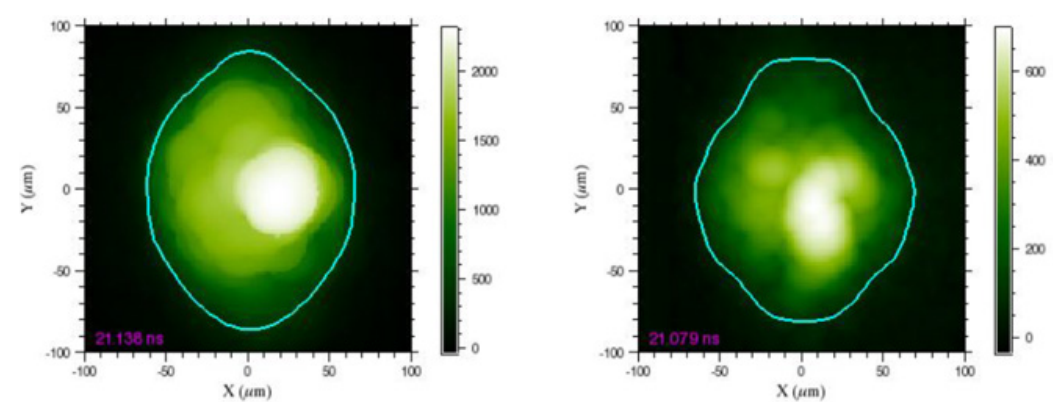

Figure 3. a) Equatorial view of $\mathrm{N} 110214$ (left) symcap with $\mathrm{P} 0=65 \pm 8 \mu \mathrm{m}$ and $\mathrm{P} 2 / \mathrm{P} 0=12 \pm 7 \%$. b) shot $\mathrm{N} 110612$ (right) having the same parameters as N110214 with $\mathrm{P} 0=60 \pm 15 \mu \mathrm{m}$ and $\mathrm{P} 2 / \mathrm{P} 0=2 \pm 8 \%$.

the laser entrance windows due to the cryogenic target temperatures. The ice buildup affects the drive during the first picket of the laser pulse which does affect the symmetry at the peak of the pulse. The ice buildup has been mitigated using a storm window added to the LEH of the target. Changes in the foot drive also affect the plasmas conditions which changes the tuning curves. Nonetheless, the data show the ability to control the symmetry using megajoule shaped laser pulses relevant to ignition.

In addition to demonstrating symmetry tuning, a test of the reproducibility has been conducted. Figure 3 shows the equatorial view of two 1.3 MJ laser shots: N110214 and N110612. The data shows the symmetry is repeatable to $10 \%$ in $\mathrm{P} 2 / \mathrm{P} 0$. The addition of the storm windows is to prevent ice build up on the laser entrance hole windows. This reduction of ice on the LEH windows was found to change the tuning for these shots.

\section{CONCLUSION}

Experiments have been carried out with 1.0 and 1.3 MJ shaped laser pulses. Control of the low mode implosion symmetry, namely dipolar component, has been demonstrated with conditions relevant for the ignition. More work is needed to control the higher order modes for this design characterized by Legendre polynomials as well as the azimuthal modes. Experiments are currently underway to address tuning of these modes.

\section{References}

[1] J. D. Lindl, Inertial confinement fusion. The quest for ignition and energy gain using indirect drive. (Springer, New York, NY, USA, 1998)

[2] M. C. Herrmann, M. Tabak, and J. D. Lindl, Phys. Plasmas 8, 2296 (2001)

[3] S. W. Haan, J. D. Lindl, D. A. Callahan et al., Phys. Plasmas 18, 051001 (2011)

[4] G. A. Kyrala, J. L. Kline, S. Dixit et al., Phys. Plasmas 18, 14 (2011)

[5] O. L. Landen, J. Edwards, S. W. Haan et al., Phys. Plasmas 18, 051002 (2011)

[6] E. Moses and C. R. Wuest, Fusion Sci. Tech. 47, 314 (2005)

[7] R. K. Kirkwood, B. B. Afeyan, W. L. Kruer et al., Phys. Rev. Lett. 76, 2065 (1996)

[8] W. Kruer, Phys. Plasmas 3, 382 (1996)

[9] S. H. Glenzer, B. J. MacGowan, P. Michel et al., Science 327, 1228 (2010)

[10] P. Michel, L. Divol, E. A. Williams et al., Phys. Rev. Lett. 102, 4 (2009)

[11] P. Michel, S. H. Glenzer, L. Divol et al., Phys. Plasmas 17, 6 (2011)

[12] R. P. J. Town, M. D. Rosen, P. A. Michel et al., Phys. Plasmas 18, 056302 (2011)

[13] N. Delamater, Phys. Plasmas 7, 1609 (2000) 


\section{IFSA 2011}

[14] C. A. Haynam, P. J. Wegner, J. M. Auerbach et al., Appl. Opt. 46, 3276 (2007)

[15] Joseph A. Menapace, Sham N. Dixit, Francois Y. Genin et al., presented at the Laser-Induced Damage in Optical Materials: 2003, Boulder, CO, USA, 2004 (unpublished)

[16] J. Oertel, R. Aragonez, T. Archuleta et al., Rev. of Sci. Instr. 77, 10 E308 (2006)

[17] G. A. Kyrala, S. Dixit, S. H. Glenzer et al., Rev. of Sci. Instr. 81, 10 E316 (2010) 